\title{
Triterpene Saponins from the Aerial Parts of Trifolium medium L. var. sarosiense
}

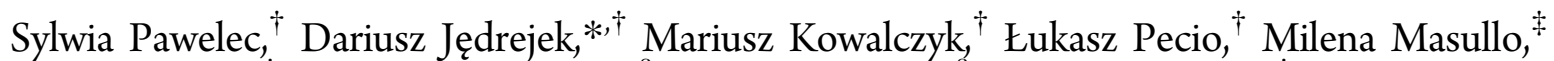
Sonia Piacente, ${ }^{\ddagger}$ Francisco A. Macías, ${ }^{\S}$ Ana M. Simonet, ${ }^{\S}$ Wiesław Oleszek, ${ }^{\dagger}$ and Anna Stochmal ${ }^{\dagger}$

${ }^{\dagger}$ Department of Biochemistry and Crop Quality, Institute of Soil Science and Plant Cultivation, State Research Institute, ul. Czartoryskich 8, 24-100 Puławy, Poland

${ }^{\ddagger}$ Department of Pharmaceutical Sciences, University of Salerno, via Ponte Don Melillo, 84084 Fisciano, Salerno, Italy

${ }^{\S}$ Department of Organic Chemistry, Faculty of Science, University of Cádiz, C/Republic Saharaui s/n, 11510 Puerto Real, Cádiz, Spain

Supporting Information

ABSTRACT: Seven previously unreported triterpene glycosides (1-7) were isolated from methanol extract of the aerial parts of Trifolium medium var. sarosiense (zigzag clover). Their structures were established by the extensive use of 1D and 2D NMR experiments along with ESI-MS and HRMS analyses. Compounds 1-7 are oleanane derivatives characterized by the presence of a keto group at C-22 of an aglycone and a primary alcoholic function at C-24 and differing functions at C-30. Among these, compounds 1-3 and 6 showed a secondary alcoholic function at C-11, which is methoxylated in compounds 4 and 7 . Compound $\mathbf{5}$ was shown to possess a known aglycone, wistariasapogenol A; however, it is described here for the first time as a saponin constituent of the Trifolium genus. Some aspects of taxonomic classification of zigzag clover are also discussed.

KEYWORDS: Trifolium medium var. sarosiense, zigzag clover, triterpene saponins

\section{INTRODUCTION}

The Fabaceae (Leguminosae) is the third largest family of flowering plants of great importance for the food industry and agriculture. It consists of 727 genera and ca. 20000 species; the Trifolium L. genus, one of the largest genera in the family, is represented by ca. 300 species. $^{1,2}$ All Trifolium species are herbaceous perennials or annuals and are widely distributed in temperate and subtropical regions of both hemispheres. ${ }^{3}$

Clovers have interest mainly as fodder and pasture crops with the target for cattle feeding. ${ }^{4,5}$ Several species of Trifolium are actively cultivated, such as Trifolium pratense, Trifolium repens, Trifolium hybridum, Trifolium subterraneum, and Trifolium fragiferum. ${ }^{1}$ A very close relative of the former is Trofolium medium, which is a rhizomatous long-lived perennial found in Eurasia from the British Isles across Europe to Turkey and Iran. ${ }^{2}$ The English name of T. medium, zigzag clover, comes from a characteristic zigzag stem branching pattern. Zigzag clover is very variable and has been divided into four varieties on the basis of flower structure and stem hairiness. Among these varieties are T. medium Grufb. var. medium and T. medium Grufb. var. sarosiense (Hazsl). The former can be found across Europe and Turkey, whereas the latter is more limited in distribution and occurs only in central Europe. However, according to some researchers, intraspecies variation in this case is far from resolved. ${ }^{2,3,67}$, Some researchers ${ }^{7,8}$ and plant databases $^{9,10}$ follow the classification of Zohary and Heller; ${ }^{2}$ nevertheless, in other publications ${ }^{6,11}$ and databases ${ }^{12,13} T$. medium var. sarosiense appears as a T. sarosiense that is classified as a taxon separate from T. medium. These two taxa nevertheless appear to be closely related and can be easily hybridized, ${ }^{8}$ although some crossing barrier in the form of hybrid chlorosis exists between them, suggesting small genetic and cytoplasmic changes. ${ }^{6,7}$ So far, the question of species rank for $T$. sarosiense is not resolved conclusively.

In recent years secondary metabolites of some clover species, especially phenolics, have been well recognized and reported. ${ }^{14-16}$ Triterpene saponins were also researched in some Trifolium species, such as $T$. pratense, $T$. repens, $T$. alexandrinum, and T. resupinatum. ${ }^{17-21}$ Earlier analyses of seeds of 57 Trifolium species ${ }^{15}$ have revealed that two subspecies of $T$. medium produce soyasapogenol aglycones, but differ in saponin composition. This is the only report about saponin content in T. medium taxa. Simultaneously, phenolic profiles of the aerial parts of T. medium var. medium and T. medium var. sarosiense have proved to be significantly different. ${ }^{16}$ On this basis, the phytochemical investigation of T. medium var. sarosiense aerial parts for saponin content and comparison between two varieties of T. medium taxa were carried out.

\section{MATERIALS AND METHODS}

Plant Material. Seeds of authenticated T. medium L. var. sarosiense were obtained from Genebank, Zentralinstitut für Pflanzengenetic und Kulturpflanzenforschung, Getersleben, Germany; referring to this source, we followed the classification of zigzag clover taxa. Plants were cultivated on the experimental field of the Institute of Soil Science and Plant Cultivation in Pulawy. The aerial parts were harvested at the beginning of flowering in July 2010, lyophilized, and finely ground. A voucher specimen (KOWAL 080721) is deposited at our laboratory.

Received: July 22, 2013

Revised: September 20, 2013

Accepted: September 20, 2013

Published: October 7, 2013 


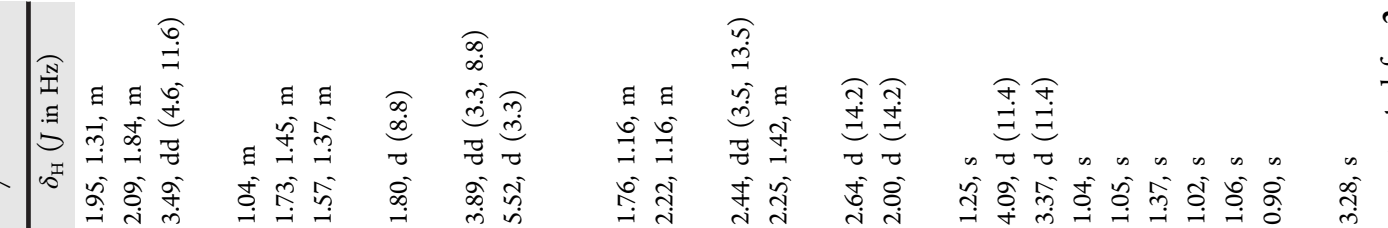

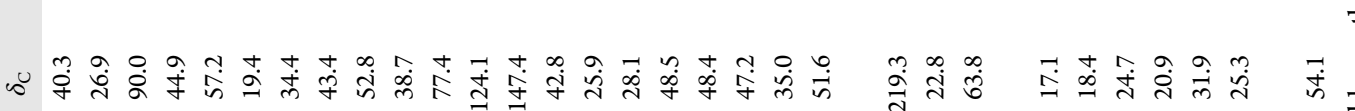

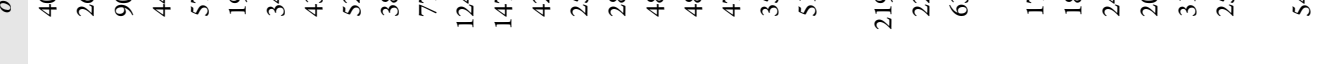

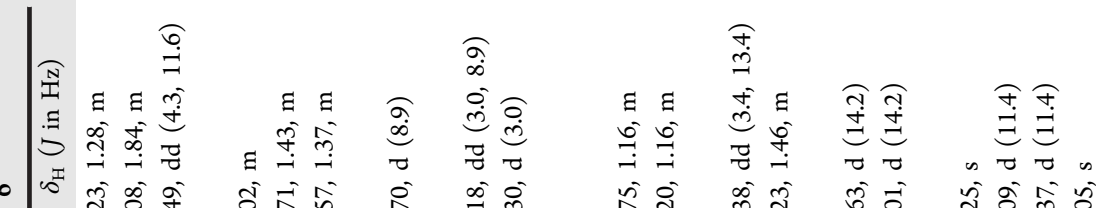

5)

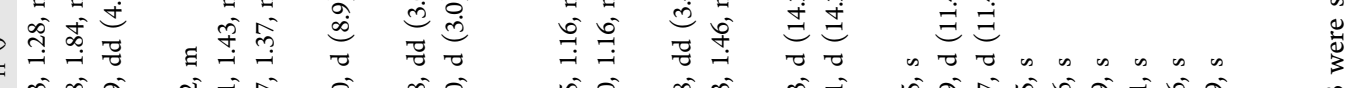

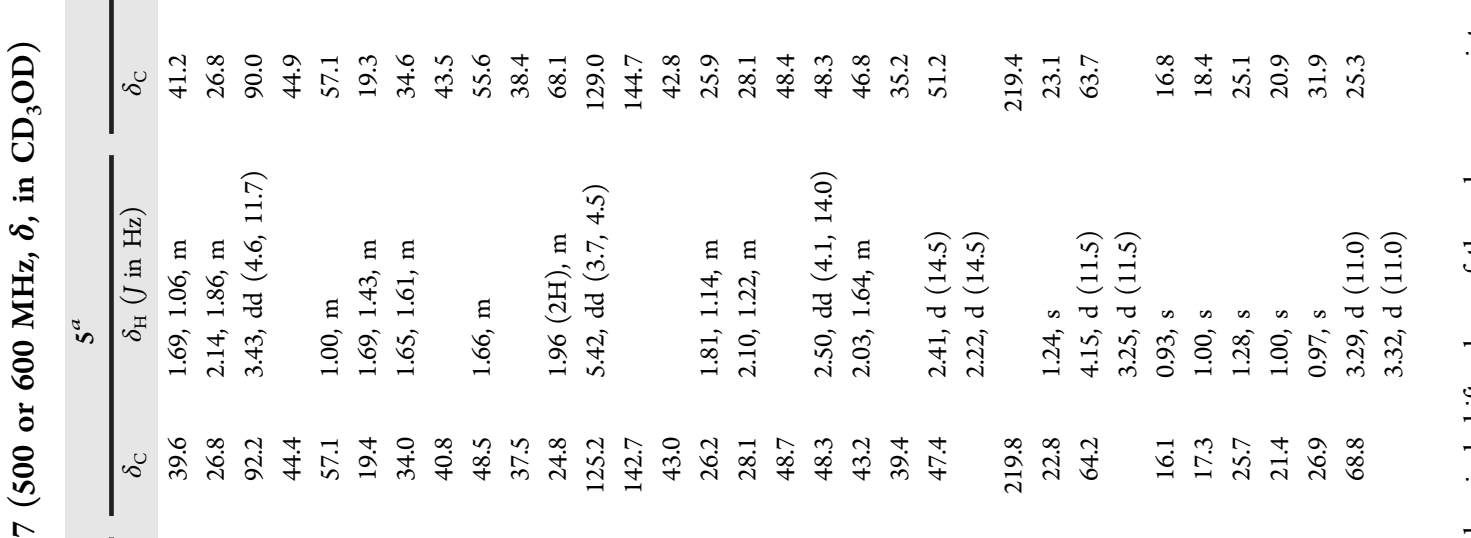

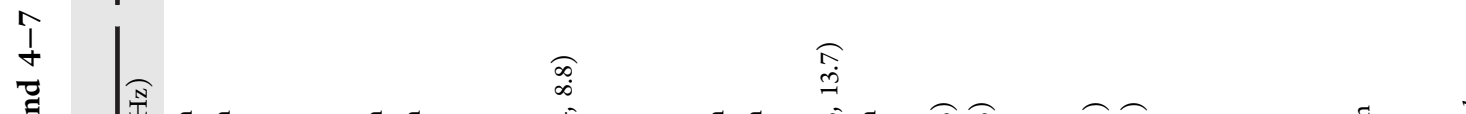

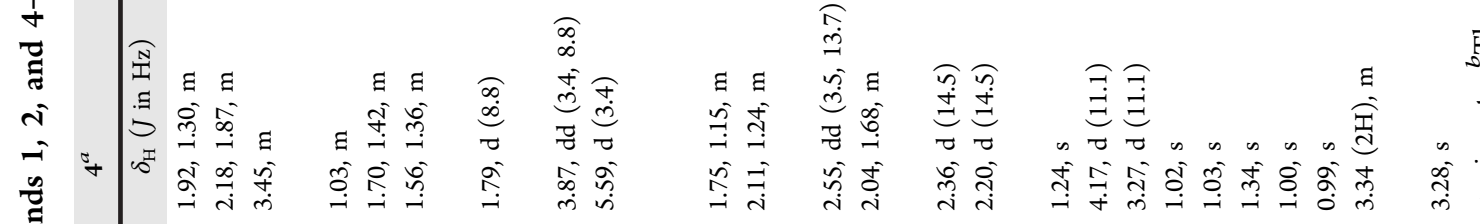

官

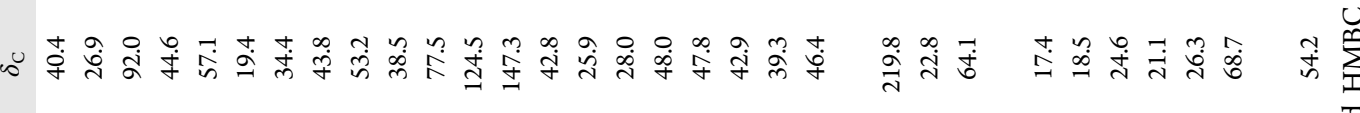

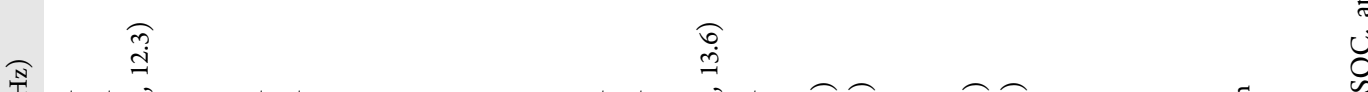

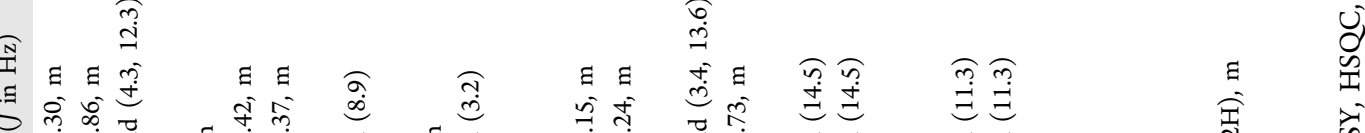

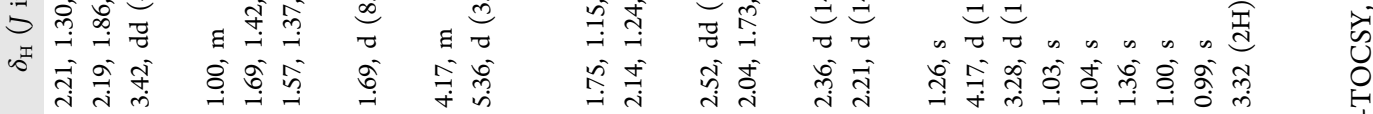

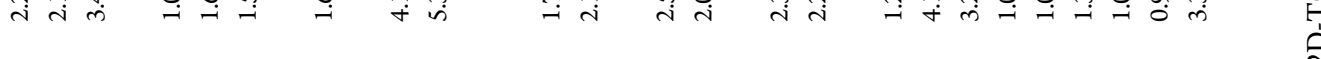

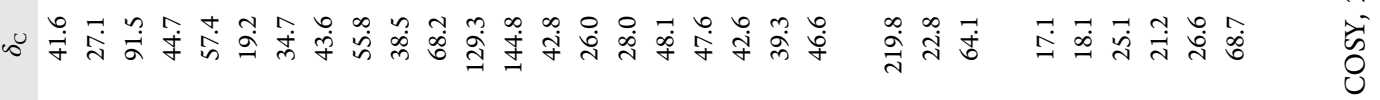

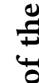

صี

(ิ)

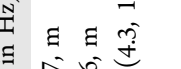

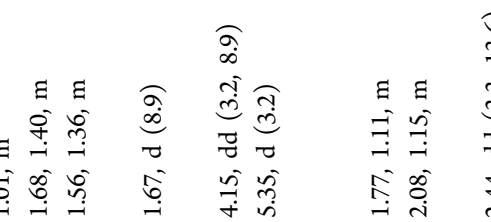

ఠิ

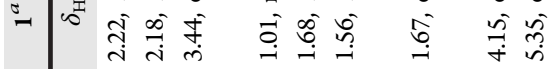

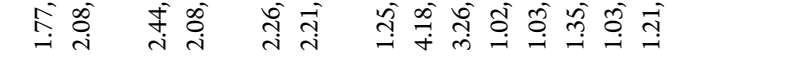

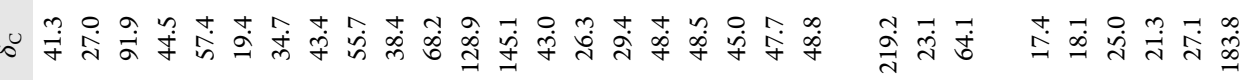


Table 2. NMR Spectroscopic Data of the Sugar Portions of Compounds 1, 2, and $6\left(500 \mathrm{MHz}, \delta\right.$, in $\left.\mathrm{CD}_{3} \mathrm{OD}\right)$

\begin{tabular}{|c|c|c|c|c|c|c|}
\hline & \multicolumn{2}{|c|}{$1^{a, b}$} & \multicolumn{2}{|r|}{$2^{a}$} & \multicolumn{2}{|c|}{$6^{a, c}$} \\
\hline & $\delta_{\mathrm{C}}$ & $\delta_{\mathrm{H}}(J$ in $\mathrm{Hz})$ & $\delta_{\mathrm{C}}$ & $\delta_{\mathrm{H}}(J$ in $\mathrm{Hz})$ & $\delta_{\mathrm{C}}$ & $\delta_{\mathrm{H}}(J$ in $\mathrm{Hz})$ \\
\hline \multicolumn{2}{|c|}{$\beta$-D-GlcA (at C-3) } & \multicolumn{2}{|c|}{$\beta$-D-GlcA (at C-3) } & \multicolumn{2}{|c|}{$\beta$-D-GlcA (at C-3) } & \\
\hline $1^{\prime}$ & 104.6 & $4.50, \mathrm{~d}(7.9)$ & 104.6 & $4.49, \mathrm{~d}(7.5)$ & 105.6 & $4.46, \mathrm{~d}(7.5)$ \\
\hline $2^{\prime}$ & 81.3 & 3.55 , dd $(7.9,9.2)$ & 81.4 & 3.35 , dd $(7.5,9.2)$ & 75.3 & 3.23 , dd $(7.5,9.0)$ \\
\hline $3^{\prime}$ & 78.5 & 3.66 , dd $(8.9,9.2)$ & 78.1 & 3.65 , dd $(9.0,9.0)$ & 77.9 & 3.41 , dd $(9.0,9.0)$ \\
\hline $4^{\prime}$ & 73.2 & 3.50 , dd $(8.9,9.7)$ & 73.1 & $3.50, \mathrm{dd}(9.0,9.0)$ & 73.7 & 3.47 , dd $(9.0,9.0)$ \\
\hline $5^{\prime}$ & 76.7 & $3.60, \mathrm{~d}(9.7)$ & 76.5 & $3.59, \mathrm{~d}(9.0)$ & 76.5 & $3.59, \mathrm{~d}(9.0)$ \\
\hline $6^{\prime}$ & 176.5 & & 176.7 & & 176.7 & \\
\hline \multicolumn{2}{|c|}{$\beta$-D-Glc (at C- $\left.2_{\mathrm{GlcA}}\right)$} & \multicolumn{2}{|c|}{$\alpha$-L-Ara (at C-2 $\left.2_{\mathrm{GlcA}}\right)$} & & & \\
\hline $1^{\prime \prime}$ & 104.2 & $4.80, \mathrm{~d}(7.5)$ & 104.3 & $4.64, \mathrm{~d}(7.7)$ & & \\
\hline $2^{\prime \prime}$ & 75.5 & 3.24 , dd $(7.5,9.0)$ & 73.1 & $3.57, \mathrm{dd}(7.7,8.5)$ & & \\
\hline $3^{\prime \prime}$ & 77.8 & $3.37, \mathrm{t}(9.0)$ & 74.3 & $3.47, \mathrm{dd}(3.0,8.5)$ & & \\
\hline $4^{\prime \prime}$ & 70.2 & $3.45, \mathrm{t}(9.0)$ & 70.2 & $3.74, \mathrm{~m}$ & & \\
\hline \multirow[t]{2}{*}{$5^{\prime \prime}$} & 77.9 & $3.23, \mathrm{~m}$ & 67.4 & 3.89 , dd $(2.0,11.9)$ & & \\
\hline & & & & 3.58 , dd $(3.0,11.9)$ & & \\
\hline \multirow[t]{2}{*}{$6^{\prime \prime}$} & 61.7 & 3.81 , dd $(3.5,12.3)$ & & & & \\
\hline & & 3.74, dd $(4.5,12.3)$ & & & & \\
\hline
\end{tabular}

${ }^{a}$ The assignments were based on ${ }^{1} \mathrm{H}-{ }^{1} \mathrm{H}$ COSY, 1D-TOCSY, HSQC, and HMBC experiments. ${ }^{b}$ The chemical shift values for the sugar portion of 3-5 were superimposable on those reported for 1 . $^{c}$ The chemical shift values for the sugar portion of 7 were superimposable on those reported for 6.

Extraction and Isolation. The powdered plant material (182 g) was defatted with chloroform $(3 \times 2 \mathrm{~L})$ in an ultrasonic bath for 30 min to remove chlorophyll and fatty acids. After drying, it was extracted under reflux for $2 \mathrm{~h}$ with $70 \%$ methanol $(2 \times 3 \mathrm{~L})$. The extract was concentrated under reduced pressure; subsequently it was suspended in water and loaded onto a LiChroprep RP18 (40-63 $\mu \mathrm{m}$, $60 \mathrm{~mm} \times 100 \mathrm{~mm}$; Merck, Darmstadt, Germany) short column equilibrated with $5 \%$ methanol. The column was washed first with water $(1.5 \mathrm{~L})$ to remove carbohydrates and subsequently with $40 \%$ $\mathrm{MeOH}(2 \mathrm{~L})$ to elute phenolic compounds. The saponin fraction was eluted with $80 \% \mathrm{MeOH}(2 \mathrm{~L})$. Evaporation of the solvent, followed by lyophilization, yielded the crude saponin fraction $(2.7 \mathrm{~g})$.

Subsequently, this fraction was dissolved in $30 \% \mathrm{MeOH}$ and applied on a preconditioned column filled with LiChroprep RP18 silica gel (40-63 $\mu \mathrm{m}, 40 \mathrm{~mm} \times 500 \mathrm{~mm}$; Merck). The gradient solvent system from 40 to $100 \% \mathrm{MeOH}$ with $5 \%$ steps was used for saponin fractionation and resulted in five fractions.

Fraction $1(16.9 \mathrm{mg})$ was separated into individual compounds on a LiChroprep Si 60 silica gel column $(25-40 \mu \mathrm{m}, 20 \mathrm{~mm} \times 500 \mathrm{~mm}$; Merck) and eluted with EtOAc/ $\mathrm{HOAc} / \mathrm{H}_{2} \mathrm{O}(9: 2: 2 \mathrm{v} / \mathrm{v} / \mathrm{v})$. Fractions $2(45 \mathrm{mg}), 3(90 \mathrm{mg}), 4(60 \mathrm{mg})$, and $5(44 \mathrm{mg})$ were separated individually on LiChroprep RP18 $(25-40 \mu \mathrm{m}, 20 \mathrm{~mm} \times 500 \mathrm{~mm}$; Merck) columns using a gradient solvent system from 30 to $100 \%$ $\mathrm{MeOH}$ with $5 \%$ steps. The aforementioned analytical methods resulted in seven pure compounds. Fraction 1 yielded compound $\mathbf{1}$ $(2.95 \mathrm{mg})$; fraction 2 , compounds $2(6.57 \mathrm{mg})$ and $3(3.99 \mathrm{mg})$; fraction 3 , compound $4(3 \mathrm{mg})$; fraction 4 , compound $5(3 \mathrm{mg})$; and fraction 5 , compounds $6(5.61 \mathrm{mg})$ and $7(11.54 \mathrm{mg})$.

Chromatographic and Mass Spectrometric Analysis. Exact masses were measured by an AB SCIEX Voyager DE mass spectrometer equipped with a $337 \mathrm{~nm}$ laser and delay extraction and operated in positive ion reflector mode. Samples were analyzed by MALDI/TOF mass spectrometry. A mixture of analyte solution and $\alpha$ cyano-4-hydroxycinnamic acid (Sigma) was applied to the metallic sample plate and dried. Mass calibration was performed with the ions from adrenocorticotropic hormone (ACTH) fragment 18-39 human at 2465.1989 Da and $\alpha$-cyano-4-hydroxycinnamic acid at $190.0504 \mathrm{Da}$ as an internal standard.

The fragmentation patterns of saponins were obtained using a Surveyor HPLC system coupled with an LCQ Advantage Max (Thermo Fisher Scientific, Waltham, MA, USA) ion trap mass spectrometer. A reverse phase Waters Xbridge BEH C18 column (2.5 $\mu \mathrm{m}, 250 \mathrm{~mm} \times 3 \mathrm{~mm})$ was used. Compounds of interest were separated using a linear $45 \mathrm{~min}$ gradient from 20 to $50 \% \mathrm{MeCN}$ in $0.1 \%$ formic acid with $0.3 \mathrm{~mL} / \mathrm{min}$ flow, and the column temperature was held at $35{ }^{\circ} \mathrm{C}$. The mass spectrometer was operated in the negative ion electrospray ionization $\left(\mathrm{ESI}^{-}\right)$mode with the following ion source parameters: sheath gas flow and auxiliary gas flow set to, respectively, 65 and 10 arbitrary units; spray needle voltage, $3.9 \mathrm{kV}$; capillary temperature, $230{ }^{\circ} \mathrm{C}$; capillary voltage, $-47 \mathrm{~V}$; tube lens offset, $-60 \mathrm{~V}$. Full scan spectra were acquired in the $\mathrm{m} / \mathrm{z}$ range from 150 to 2000. MS/MS analyses were performed with the normalized collision energy of $35 \%$ and scanning range from the "cut-off" mass (approximately one-third of the parent mass) up to 10 mass units above the parent mass and the maximum ion inject time of $250 \mathrm{~ms}$. Data acquisition was conducted using the Xcalibur data system (version 1.3 SR1, Thermo Fisher Scientific).

GC analysis was performed on a Thermo Finnigan Trace GC apparatus using a l-Chirasil-Val column $(0.32 \mathrm{~mm} \times 25 \mathrm{~m})$.

TLC was performed on silica gel $60 \mathrm{~F}_{254}$ plates (Merck), and the solvent system EtOAc/HOAc/ $\mathrm{H}_{2} \mathrm{O}(7: 2: 2 \mathrm{v} / \mathrm{v} / \mathrm{v})$ was used for analysis. Spots were revealed by spraying with a LiebermannBurchard agent, followed by heating at $150{ }^{\circ} \mathrm{C}$. Column chromatography was carried out using silica gel (LiChroprep Si 60, 25-40 $\mu \mathrm{m}$ ) (Merck) and RP-18 silica gel (Lichroprep RP18, 40-63 or 25-40 $\mu \mathrm{m}$ ) (Merck).

Optical rotations were measured on a Jasco P 2000 digital polarimeter. IR measurements were performed on a Bruker IFS-48 spectrometer.

NMR Measurements. 1D and 2D NMR spectra were recorded either on a Bruker Avance- 500 spectrometer equipped with a $5 \mathrm{~mm}$ indirect detection probe or on a Varian INOVA-600 spectrometer equipped with a $5 \mathrm{~mm}$ indirect detection probe. The ${ }^{1} \mathrm{H}$ and ${ }^{13} \mathrm{C}$ NMR spectra (at 500 or 600 and 125 or $150 \mathrm{MHz}$, respectively) were measured in methanol- $d_{4}$ at $300 \mathrm{~K}$. Chemical shifts are given on the $\delta$ scale and referenced to residual methanol, $\delta{ }^{1} \mathrm{H} 3.34$ and ${ }^{13} \mathrm{C} 49.00$.

Determination of Absolute Configuration of Sugars. The configuration of sugar units was established after hydrolysis of 1-7, with $1 \mathrm{~N} \mathrm{HCl}$, trimethylsilation, and determination of the retention times by GC operating in the experimental conditions previously reported by De Marino et al. ${ }^{28}$

The peaks of silylated D-glucuronic acid (15.83 min) and silylated Dglucose $(14.74 \mathrm{~min})$ were detected in the hydrolysate of 1 . The peaks of silylated L-arabinose (8.94 and $9.81 \mathrm{~min}$ ) and silylated D-glucuronic 
acid $(15.82 \mathrm{~min})$ were detected in the hydrolysate of 2 . Retention times for authentic samples after being treated in the same manner with 1-(trimethylsilyl)imidazole in pyridine were detected at 8.92 and $9.80 \mathrm{~min}$ (silylated L-arabinose), $14.71 \mathrm{~min}$ (silylated D-glucose), and $15.81 \mathrm{~min}$ (silylated D-glucuronic acid).

Chemical Data of Saponins 1-7. Saponin 1: amorphous white solid; $\mathrm{C}_{42} \mathrm{H}_{64} \mathrm{O}_{17} ;[\alpha]^{25}{ }_{\mathrm{D}}-9.1^{\circ}(c 0.1 \mathrm{MeOH}) ; \mathrm{IR} \nu^{\mathrm{KBr}}{ }_{\max } \mathrm{cm}^{-1} 3430$ $(\mathrm{OH}), 2925(\mathrm{CH}), 1680(\mathrm{C}=\mathrm{O}), 1656(\mathrm{C}=\mathrm{C})$; for ${ }^{1} \mathrm{H}$ and ${ }^{13} \mathrm{C}$ NMR $\left(\mathrm{CD}_{3} \mathrm{OD}, 500 \mathrm{MHz}\right)$ data of the aglycone moiety and the sugar portion see Tables 1 and 2, respectively; ESI-MS $m / z$ 839.4 [M $\mathrm{H}]^{-}$; ESI-MS/MS $m / z 677.3[(\mathrm{M}-\mathrm{H})-162]^{-}, 501.2[(\mathrm{M}-\mathrm{H})-$ $162-176]^{-} ;$HR-MALDI/TOF-MS $[\mathrm{M}+\mathrm{Na}]^{+} \mathrm{m} / z 863.4043$ (calcd for $\mathrm{C}_{42} \mathrm{H}_{64} \mathrm{O}_{17} \mathrm{Na}, 863.4041$ ).

Saponin 2: amorphous white solid; $\mathrm{C}_{41} \mathrm{H}_{64} \mathrm{O}_{15} ;[\alpha]^{25}+30.1^{\circ}(c$ $0.05 \mathrm{MeOH})$; IR $\nu^{\mathrm{KBr}}{ }_{\max } \mathrm{cm}^{-1} 3440(\mathrm{OH}), 2935(\mathrm{CH}), 1670(\mathrm{C}=\mathrm{O})$, $1655(\mathrm{C}=\mathrm{C})$; for ${ }^{1} \mathrm{H}$ and ${ }^{13} \mathrm{C} \mathrm{NMR}\left(\mathrm{CD}_{3} \mathrm{OD}, 500 \mathrm{MHz}\right)$ data of the aglycone moiety and the sugar portion see Tables 1 and 2, respectively; ESI-MS $m / z 795.4[\mathrm{M}-\mathrm{H}]^{-}$; ESI-MS/MS $m / z 663.4$ $[(\mathrm{M}-\mathrm{H})-132]^{-}, 487.3[(\mathrm{M}-\mathrm{H})-132-176]^{-}$; HR-MALDI/ TOF-MS $[\mathrm{M}+\mathrm{Na}]^{+} \mathrm{m} / z 819.4146$ (calcd for $\mathrm{C}_{41} \mathrm{H}_{64} \mathrm{O}_{15} \mathrm{Na}$, 819.4143).

Saponin 3: amorphous white solid; $\mathrm{C}_{42} \mathrm{H}_{66} \mathrm{O}_{16} ;[\alpha]^{25}-8.3^{\circ}(c 0.1$ $\mathrm{MeOH})$; IR $\nu_{\text {max }}^{\mathrm{KBr}} \mathrm{cm}^{-1} 3450(\mathrm{OH}), 2935(\mathrm{CH}), 1680(\mathrm{C}=\mathrm{O})$, $1660(\mathrm{C}=\mathrm{C})$; for ${ }^{1} \mathrm{H}$ and ${ }^{13} \mathrm{C}$ NMR $\left(\mathrm{CD}_{3} \mathrm{OD}, 500 \mathrm{MHz}\right)$ data of the aglycone moiety and the sugar portion see Tables and 2, respectively; ESI-MS $m / z$ 825.5 $\left[\mathrm{M}-\mathrm{H}^{-}\right]^{-}$; ESI-MS/MS $m / z 663.4[(\mathrm{M}-\mathrm{H})-$ $162]^{-}$, $487.4[(\mathrm{M}-\mathrm{H})-162-176]^{-}$; HR-MALDI/TOF-MS [M + $\mathrm{Na}]^{+} m / z 849.4253$ (calcd for $\mathrm{C}_{42} \mathrm{H}_{66} \mathrm{O}_{16} \mathrm{Na}, 849.4249$ ).

Saponin 4: amorphous white solid; $\mathrm{C}_{43} \mathrm{H}_{68} \mathrm{O}_{16} ;[\alpha]^{25}{ }_{D}-17.0^{\circ}(c$ $0.1 \mathrm{MeOH})$; IR $\nu^{\mathrm{KBr}}{ }_{\max } \mathrm{cm}^{-1} 3430(\mathrm{OH}), 2948(\mathrm{CH}), 1670(\mathrm{C}=\mathrm{O})$, $1656(\mathrm{C}=\mathrm{C})$; for ${ }^{1} \mathrm{H}$ and ${ }^{13} \mathrm{C}$ NMR $\left(\mathrm{CD}_{3} \mathrm{OD}, 600 \mathrm{MHz}\right)$ data of the aglycone moiety and the sugar portion see Tables 1 and 2, respectively; ESI-MS $m / z$ 839.4 [M - H] ${ }^{-}$; ESI-MS/MS $m / z 677.4$ $[(\mathrm{M}-\mathrm{H})-162]^{-}, 501.3[(\mathrm{M}-\mathrm{H})-162-176]^{-}$; HR-MALDI/ TOF-MS $[\mathrm{M}+\mathrm{Na}]^{+} \mathrm{m} / z 863.4409$ (calcd for $\mathrm{C}_{43} \mathrm{H}_{68} \mathrm{O}_{16} \mathrm{Na}$, 863.4405)

Saponin 5: amorphous white solid; $\mathrm{C}_{43} \mathrm{H}_{68} \mathrm{O}_{16} ;[\alpha]^{25}+10.6^{\circ}(c 0.1$ $\mathrm{MeOH})$; IR $\nu_{\text {max }}^{\mathrm{KBr}} \mathrm{cm}^{-1} 3435(\mathrm{OH}), 2925(\mathrm{CH}), 1670(\mathrm{C}=\mathrm{O})$, $1656(\mathrm{C}=\mathrm{C})$; for ${ }^{1} \mathrm{H}$ and ${ }^{13} \mathrm{C}$ NMR $\left(\mathrm{CD}_{3} \mathrm{OD}, 600 \mathrm{MHz}\right)$ data of the aglycone moiety and the sugar portion see Tables 1 and 2, respectively; ESI-MS $m / z$ 809.4 $[\mathrm{M}-\mathrm{H}]^{-}$; ESI-MS/MS $m / z 647.3$ $[(\mathrm{M}-\mathrm{H})-162]^{-}, 471.2[(\mathrm{M}-\mathrm{H})-162-176]^{-}$; HR-MALDI/ TOF-MS $[\mathrm{M}+\mathrm{Na}]^{+} m / z 833.4252$ (calcd for $\mathrm{C}_{42} \mathrm{H}_{66} \mathrm{O}_{15} \mathrm{Na}$, 833.4249).

Saponin 6: amorphous white solid; $\mathrm{C}_{36} \mathrm{H}_{56} \mathrm{O}_{10} ;[\alpha]^{25}{ }_{\mathrm{D}}-14.6^{\circ}(c$ $0.05 \mathrm{MeOH})$; IR $\nu^{\mathrm{KBr}}{ }_{\max } \mathrm{cm}^{-1} 3443(\mathrm{OH}), 2935(\mathrm{CH}), 1670(\mathrm{C}=\mathrm{O})$, $1655(\mathrm{C}=\mathrm{C})$; for ${ }^{1} \mathrm{H}$ and ${ }^{13} \mathrm{C} \mathrm{NMR}\left(\mathrm{CD}_{3} \mathrm{OD}, 500 \mathrm{MHz}\right)$ data of the aglycone moiety and the sugar portion see Tables 1 and 2, respectively; ESI-MS $m / z 647.4[\mathrm{M}-\mathrm{H}]^{-}$; ESI-MS/MS $m / z 471.3$ $[(\mathrm{M}-\mathrm{H})-176]^{-}$; HR-MALDI/TOF-MS $[\mathrm{M}+\mathrm{Na}]^{+} \mathrm{m} / z 671.3774$ (calcd for $\mathrm{C}_{36} \mathrm{H}_{56} \mathrm{O}_{10} \mathrm{Na}, 671.3771$ ).

Saponin 7: amorphous white solid; $\mathrm{C}_{36} \mathrm{H}_{56} \mathrm{O}_{10} ;[\alpha]^{25}-40.1^{\circ}(c$ $0.08 \mathrm{MeOH})$; IR $\nu^{\mathrm{KBr}}{ }_{\text {max }} \mathrm{cm}^{-1} 3430(\mathrm{OH}), 2938(\mathrm{CH}), 1670(\mathrm{C}=\mathrm{O})$, $1650(\mathrm{C}=\mathrm{C})$; for ${ }^{1} \mathrm{H}$ and ${ }^{13} \mathrm{C} \mathrm{NMR}\left(\mathrm{CD}_{3} \mathrm{OD}, 500 \mathrm{MHz}\right)$ data of the aglycone moiety and the sugar portion see Tables 1 and 2, respectively; ESI-MS $m / z 661.3[\mathrm{M}-\mathrm{H}]^{-}$; ESI-MS/MS $m / z 485.2$ $[(\mathrm{M}-\mathrm{H})-176]^{-}$; HR-MALDI/TOF-MS $[\mathrm{M}+\mathrm{Na}]^{+} \mathrm{m} / z 685.3932$ (calcd for $\mathrm{C}_{37} \mathrm{H}_{58} \mathrm{O}_{10} \mathrm{Na}, 685.3928$ ).

\section{RESULTS AND DISCUSSION}

Structure Elucidation. The powdered aerial parts of $T$. medium var. sarosiense, after defatting with chloroform, were extracted with $\mathrm{MeOH}$, and the obtained extract was fractionated by different chromatographic steps to yield seven compounds (1-7) (Figure 1).

The HR-MALDI/TOF mass spectrum of $\mathbf{6}$ supported a molecular formula of $\mathrm{C}_{36} \mathrm{H}_{56} \mathrm{O}_{10}$. The negative ESI-MS spectrum showed the ion peak at $\mathrm{m} / z$ 647.4, which was
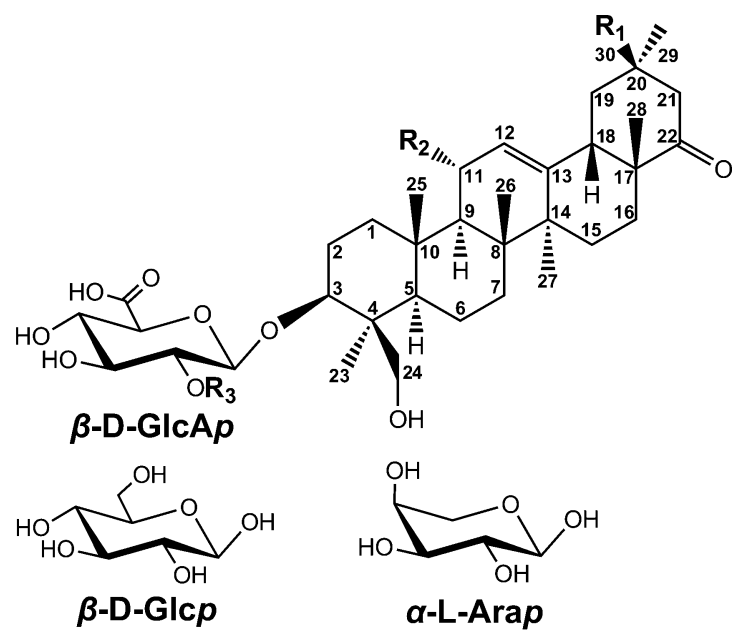

\begin{tabular}{cccc}
\hline Compound & $\mathbf{R}_{\mathbf{1}}$ & $\mathbf{R}_{\mathbf{2}}$ & $\mathbf{R}_{\mathbf{3}}$ \\
\hline $\mathbf{1}$ & $\mathrm{COOH}$ & $\mathrm{OH}$ & $\beta$-D-Glcp \\
$\mathbf{2}$ & $\mathrm{CH}_{2} \mathrm{OH}$ & $\mathrm{OH}$ & $\alpha$-L-Arap \\
$\mathbf{3}$ & $\mathrm{CH}_{2} \mathrm{OH}$ & $\mathrm{OH}$ & $\beta$-D-Glcp \\
$\mathbf{4}$ & $\mathrm{CH}_{2} \mathrm{OH}$ & $\mathrm{OCH}_{3}$ & $\beta$-D-Glcp \\
$\mathbf{5}$ & $\mathrm{CH}_{2} \mathrm{OH}$ & $\mathrm{H}$ & $\beta$-D-Glcp \\
$\mathbf{6}$ & $\mathrm{CH}_{3}$ & $\mathrm{OH}$ & $\mathrm{H}$ \\
$\mathbf{7}$ & $\mathrm{CH}_{3}$ & $\mathrm{OCH}$ & $\mathrm{H}$ \\
\hline
\end{tabular}

Figure 1. Compounds 1-7 isolated from Trifolium medium var. sarosiense aerial parts.

assigned to $[\mathrm{M}-\mathrm{H}]^{-}$. The $\mathrm{MS} / \mathrm{MS}$ of this ion showed fragmentation ion peak at $m / z 471.3[(\mathrm{M}-\mathrm{H})-176]^{-}$, corresponding to the loss of a hexuronic acid.

The ${ }^{13} \mathrm{C}$ NMR spectrum showed the presence of 36 carbon signals; thus, considering 6 carbon signals for a sugar unit, shown to be present from the MS fragmentation, 30 of them were assigned to the triterpene aglycone (Table 1). ${ }^{22}$ Chemical shifts of two olefinic carbons at $\delta_{\mathrm{C}} 129.0$ (C-12) and 144.7 (C$13)$, characteristic for a $\Delta^{12}-\beta$-amyrin skeleton, were observed. ${ }^{23}$ Signals at $\delta_{\mathrm{C}} 16.8,18.4,20.9,23.1,25.1,25.3$, and 31.9 ascribable to seven methyl groups, along with a signal at $\delta_{\mathrm{C}} 63.7$ due to a primary alcoholic function, could be also observed. Furthermore, the carbon spectrum displayed signals at $\delta_{\mathrm{C}} 90.0$ and 68.1 assigned to secondary alcoholic functions and at $\delta_{\mathrm{C}}$ 219.4 , suggesting the occurrence of a keto group. The ${ }^{1} \mathrm{H}$ NMR spectrum of 6 (Table 1) showed signals for seven tertiary methyl groups at $\delta_{\mathrm{H}} 0.89,1.01,1.05,1.06(6 \mathrm{H}), 1.25$, and 1.39, one olefinic proton at $\delta_{\mathrm{H}} 5.30(\mathrm{~d}, J=3.0 \mathrm{~Hz}, \mathrm{H}-12)$, two oxymethine protons at $\delta_{\mathrm{H}} 3.49(\mathrm{dd}, J=4.3,11.6 \mathrm{~Hz})$ and 4.18 (dd, $J=3.0,8.9 \mathrm{~Hz}$ ), and two geminal oxymethylene protons at $\delta_{\mathrm{H}} 3.37$ and 4.09 (each, d, $J=11.4 \mathrm{~Hz}$ ). The secondary alcoholic function at $\delta_{\mathrm{C}} 90.0$ was attributed to C-3, and the coupling constants of the corresponding proton at $\delta_{\mathrm{H}} 3.49(\mathrm{dd}$, $J=4.3,11.6 \mathrm{~Hz})$, together with ROESY correlation between $\mathrm{H}$ 3 and the proton resonance at $\delta_{\mathrm{H}} 1.02(1 \mathrm{H}, m, \mathrm{H}-5)$ allowed a $3 \beta$-OH orientation to be deduced. The downfield shift of C-3 $\left(\delta_{\mathrm{C}} 90.0\right)$ suggested the occurrence of a glycosidation at this position. The additional secondary alcoholic group was located at $\mathrm{C}-11$ on the basis of COSY correlations between the proton at $\delta_{\mathrm{H}} 4.18$ with the proton resonance at $5.30(\mathrm{~d}, J=3.0 \mathrm{~Hz}, \mathrm{H}$ $12)$, and according to HMBC correlations between the proton signal at $\delta 4.18$ and the carbon resonances at $\delta_{\mathrm{C}} 55.6$ (C-9) and 129.0 (C-12). ROESY experiment, which showed correlations 
between $\mathrm{H}-11$ and the protons at $\delta_{\mathrm{H}} 1.05(\mathrm{Me}-25)$ and 1.06 (Me-26), allowed us to establish the $\alpha$ orientation of a secondary alcoholic function at C-11. This result was in agreement with literature data. ${ }^{24,25}$ The proton resonances of a primary alcoholic function at $\delta_{\mathrm{H}} 3.37$ and 4.09 showed $\mathrm{HMBC}$ correlations with the carbon signals at $\delta_{\mathrm{C}} 90.0$ (C-3), 44.9 (C4), 57.1 (C-5), and 23.1 (C-23) and identified the attachment site of a $\mathrm{CH}_{2} \mathrm{OH}$ group as $\mathrm{C}-4$. The $24-\mathrm{CH}_{2} \mathrm{OH}\left(\delta_{\mathrm{C}} 63.7\right)$ could be derived from the chemical shift of the methyl group $\left(\delta_{\mathrm{C}} 23.1\right)$, which is reported as upfield shifted $\left(\delta_{\mathrm{C}} 14.0\right)$ in the case of $23-\mathrm{CH}_{2} \mathrm{OH}^{24}$ ROESY correlations between the proton values of the secondary alcoholic function at C-24 $\left(\delta_{\mathrm{H}} 3.37\right.$ and $4.09)$ with the proton resonance at $\delta_{\mathrm{H}} 1.05(\mathrm{Me}-25)$ confirmed the occurrence of a $24-\mathrm{CH}_{2} \mathrm{OH}$. The reciprocated correlations on the HMBC spectrum between two Me groups $\left(\delta_{\mathrm{C}} 25.3\right.$ and $\delta_{\mathrm{H}} 0.89, \mathrm{~s}$; and $\delta_{\mathrm{C}} 31.9$ and $\left.\delta_{\mathrm{H}} 1.06, \mathrm{~s}\right)$, as well as $\mathrm{HMBC}$ correlations of their proton signals with the carbon resonances at $\delta_{\mathrm{C}} 46.8(\mathrm{C}-19), 35.2(\mathrm{C}-20)$, and $51.2(\mathrm{C}-21)$, suggested the linkage of both methyl groups to C-20. Literature data report for aglycones possessing a methyl group at positions C-29 and C-30 the chemical shift of the Me-29 of $\sim 32.0$ ppm and $\sim 25.0$ ppm for Me-30. ${ }^{26,27}$ ROESY experiment, in which correlations between the proton resonance at $\delta_{\mathrm{H}} 2.38(\mathrm{dd}, J=3.4,13.4 \mathrm{~Hz}$, $\mathrm{H}-18)$ and the proton at $\delta_{\mathrm{H}} 0.89(\mathrm{Me}-30)$ and between the proton value at $\delta_{\mathrm{H}} 1.06(\mathrm{Me}-29)$ and both $\mathrm{H}-19$ protons $\left(\delta_{\mathrm{H}}\right.$ 1.46 and 2.23 , each, $\mathrm{m}$ ) could be observed, supported the aforementioned orientation of the methyl groups linked to $\mathrm{C}$ 20. The keto group was located at C-22 on the basis of the $\mathrm{HMBC}$ correlations between the carbon signal at $\delta_{\mathrm{C}} 219.4$ and proton resonances at $\delta_{\mathrm{H}} 1.01(\mathrm{Me}-28), 2.01(\mathrm{~d}, J=14.2 \mathrm{~Hz}, \mathrm{H}$ $21)$, and $2.63(\mathrm{~d}, J=14.2 \mathrm{~Hz}, \mathrm{H}-21)$.

For the sugar portion, compound $\mathbf{6}$ showed a signal corresponding to the one anomeric proton at $\delta_{\mathrm{H}} 4.46(\mathrm{~d}, J=$ $7.5 \mathrm{~Hz}$ ) (Table 2). On the basis of $2 \mathrm{D}$ NMR data, a $\beta$ glucuronopyranosyl unit was identified. The determination of a linkage site was obtained from the HMBC correlation between the proton signal at $\delta_{\mathrm{H}} 4.46\left(\mathrm{H}-1_{\mathrm{GlcA}}\right)$ and the carbon resonance at $\delta_{\mathrm{C}} 90.0$ (C-3). The D configuration of the glucuronic acid unit was established after hydrolysis of 6 followed by GC analysis. ${ }^{28}$ Thus, the structure of 6 was elucidated as the new 3-O- $\beta$-D-glucuronopyranosyl-3 $\beta, 11 \alpha, 24$ trihydroxyolean-12-en-22-one, and the proposed trivial name is sarosiensin VI.

The HR-MALDI/TOF mass spectrum of 7 supported a molecular formula of $\mathrm{C}_{41} \mathrm{H}_{64} \mathrm{O}_{15}$. The ESI-MS mass spectrum showed the major ion peak at $m / z 661.3$, which was assigned to $[\mathrm{M}-\mathrm{H}]^{-}$. Its MS/MS showed a fragmentation ion peak at $\mathrm{m} /$ $z 485.2[(\mathrm{M}-\mathrm{H})-176]^{-}$, corresponding to the loss of a hexuronic acid.

Comparison of the ${ }^{1} \mathrm{H}$ and ${ }^{13} \mathrm{C}$ NMR spectroscopic data of 7 and 6 showed superimposable resonances, except for the presence of the signal at $\delta_{\mathrm{H}} 3.28(3 \mathrm{H}, \mathrm{s})$ with $\delta_{\mathrm{C}} 54.1$ corresponding to a methoxyl group. This function was located at $\mathrm{C}-11$ on the basis of HMBC correlation between the proton value at $\delta_{\mathrm{H}} 3.28$ and the carbon resonance at $\delta_{\mathrm{C}} 77.4(\mathrm{C}-11)$. The orientation of the 11-OMe group was established as $\alpha$ according to the ROESY spectrum, in which correlations between the proton signal at $\delta_{\mathrm{H}} 3.89(\mathrm{dd}, J=3.3,8.8 \mathrm{~Hz}, \mathrm{H}-11)$ with the proton resonances at $\delta_{\mathrm{H}} 1.04(\mathrm{Me}-25)$ and $1.05(\mathrm{Me}-$ 26) could be observed. This result was in agreement with reported data. ${ }^{25}$ Consequently, compound 7 was identified as 3-O- $\beta$-D-glucuronopyranosyl-3 $\beta, 24$-dihydroxy-1 $1 \alpha$-methoxyo- lean-12-en-22-one, and the proposed trivial name is sarosiensin VII.

The HR-MALDI/TOF mass spectrum of 2 supported a molecular formula of $\mathrm{C}_{41} \mathrm{H}_{64} \mathrm{O}_{15}$. The ESI-MS mass spectrum in the negative ion mode showed the major ion peak at $\mathrm{m} / \mathrm{z}$ 795.4, which was assigned to $[\mathrm{M}-\mathrm{H}]^{-}$. The MS/MS fragmentation spectrum of this ion showed ions at $\mathrm{m} / \mathrm{z} 645.2$ $[\mathrm{M}-\mathrm{H}-150]^{-}, 487.3[\mathrm{M}-\mathrm{H}-308]^{-}$, corresponding to losses of a pentose and a pentose-hexuronic acid disaccharide, respectively.

A detailed comparison of NMR spectroscopic data of the aglycone portion of $\mathbf{2}$ and $\mathbf{6}$ showed great similarity, and the only observed difference was the presence of an additional primary alcoholic function at C-30 $\left(\delta_{\mathrm{C}} 68.7\right.$ and $\delta_{\mathrm{H}} 3.32,2 \mathrm{H}$, $\mathrm{m})$ in 2 , instead of the methyl group in 6 . The linkage of the $\mathrm{CH}_{2} \mathrm{OH}$ group to $\mathrm{C}-20$ was determined from the HMBC spectrum, in which correlations between the carbon resonance at $\delta_{\mathrm{C}} 68.7$ with the proton signals at $\delta_{\mathrm{H}} 0.99(\mathrm{Me}-29)$ and $\delta$ 1.73 and 2.03 (each, $\mathrm{m}, \mathrm{H}-19$ ) could be observed. The ROESY spectrum showed correlations between the signal of Me-29 $\left(\delta_{\mathrm{H}}\right.$ $0.99)$ with both $\mathrm{H}-19$ protons $\left(\delta_{\mathrm{H}} 1.73\right.$ and 2.04$)$, as well as correlations between the proton resonance at $\delta_{\mathrm{H}} 3.32(2 \mathrm{H}, \mathrm{H}-$ $30)$ with the proton signal at $\delta_{\mathrm{H}} 2.52(\mathrm{dd}, J=3.4,13.6 \mathrm{~Hz}, \mathrm{H}-$ 18 ), thus allowing us to establish the $\beta$ orientation of an additional primary alcoholic function. Our results are consistent with those reported in the literature. ${ }^{26,29,30}$

For the sugar portion compound 2 showed in the ${ }^{1} \mathrm{H}$ NMR spectrum signals corresponding to two anomeric protons at $\delta_{\mathrm{H}}$ $4.49(\mathrm{~d}, J=7.5 \mathrm{~Hz})$, and $4.64(\mathrm{~d}, J=7.5 \mathrm{~Hz})($ Table 2). On the basis of $2 \mathrm{D}$ NMR data one $\alpha$-arabinopyranosyl $\left(\delta_{\mathrm{H}} 4.64\right)$ and one $\beta$-glucuronic acid $\left(\delta_{\mathrm{H}} 4.49\right)$ units were identified. The determination of sequence and linkage sites was obtained from the HMBC correlations between the proton signal at $\delta_{\mathrm{H}} 4.64$ $\left(\mathrm{H}-1_{\mathrm{Ara}}\right)$ with the carbon resonance at $\delta_{\mathrm{C}} 81.4\left(\mathrm{C}-2_{\mathrm{GlcA}}\right)$ and between the signal at $\delta_{\mathrm{H}} 4.49\left(\mathrm{H}-1_{\mathrm{GlcA}}\right)$ with the carbon value at $\delta_{\mathrm{C}} 91.5(\mathrm{C}-3)$. The D configuration of the glucuronic acid and the $\mathrm{L}$ configuration of the arabinose units were established after hydrolysis of 2 followed by GC analysis. ${ }^{28}$ On this basis, the structure of 2 was determined as 3-O-[ $\alpha$-L-arabinopyranosyl$(1 \rightarrow 2)$ - $\beta$-D-glucuronopyranosyl]-3 $\beta, 11 \alpha, 24,30$-tetrahydroxyolean-12-en-22-one, and the proposed trivial name is sarosiensin II.

The molecular formula of 3 was established as $\mathrm{C}_{42} \mathrm{H}_{66} \mathrm{O}_{16}$ by HR-MALDI/TOF mass spectrum. The ESI-MS mass spectrum in the negative ion mode showed the major ion peak at $\mathrm{m} / \mathrm{z}$ 825.5, which was assigned to $[\mathrm{M}-\mathrm{H}]^{-}$. During $\mathrm{MS} / \mathrm{MS}$ fragmentation, it produced ions at $m / z 645.2[\mathrm{M}-\mathrm{H}-$ $180]^{-}$and at $\mathrm{m} / \mathrm{z} 487.4[\mathrm{M}-\mathrm{H}-338]^{-}$, corresponding to losses of a hexose and a hexose-hexuronic acid disaccharide.

A detailed comparison of NMR spectroscopic data for the aglycone portion of compounds $\mathbf{3}$ and $\mathbf{2}$ demonstrated superimposable resonances, and it was concluded that both compounds possessed the same aglycone moiety.

For the sugar portion, compound 3 showed signals corresponding to two anomeric protons at $\delta_{\mathrm{H}} 4.50(\mathrm{~d}, J=$ $7.9 \mathrm{~Hz}$ ) and $4.80(\mathrm{~d}, J=7.5 \mathrm{~Hz})$ (Table 2$)$. On the basis of $2 \mathrm{D}$ NMR data, one $\beta$-glucopyranosyl $\left(\delta_{\mathrm{H}} 4.80\right)$ and one $\beta$ glucuronopyranosyl $\left(\delta_{\mathrm{H}} 4.50\right)$ units were identified. The determination of sequence and linkage sites was obtained from the HMBC correlations between the proton signal at $\delta_{\mathrm{H}}$ $4.80\left(\mathrm{H}-1_{\mathrm{Glc}}\right)$ and the carbon resonance at $\delta_{\mathrm{C}} 81.3\left(\mathrm{C}-2_{\mathrm{GlcA}}\right)$ and between the signal at $\delta_{\mathrm{H}} 4.50\left(\mathrm{H}-1_{\mathrm{GlcA}}\right)$ and the carbon resonance at $\delta_{\mathrm{C}} 91.5(\mathrm{C}-3)$. The D configuration of the glucose 
and glucuronic acid units was established after hydrolysis of 3 followed by GC analysis. ${ }^{28}$ Therefore, compound 3 was identified as $3-O-[\beta$-D-glucopyranosyl- $(1 \rightarrow 2)-\beta$-D-glucuronopyranosyl]-3 $\beta, 11 \alpha, 24,30$-tetrahydroxyolean-12-en-22-one, and the proposed trivial name is sarosiensin III.

The HR-MALDI/TOF mass spectrum of $\mathbf{4}$ showed a major ion peak at $m / z$ 863.4409 $[\mathrm{M}+\mathrm{Na}]^{+}$ascribable to the molecular formula $\mathrm{C}_{43} \mathrm{H}_{68} \mathrm{O}_{16}$ (calcd for $\mathrm{C}_{43} \mathrm{H}_{68} \mathrm{O}_{16} \mathrm{Na}$, 863.4405). The negative ESI-MS spectrum showed the ion peak at $m / z 839.4$, which was assigned to $[\mathrm{M}-\mathrm{H}]^{-}$. The MS/ MS of this ion was essentially identical to that of 3 .

Comparison of the ${ }^{1} \mathrm{H}$ and ${ }^{13} \mathrm{C}$ NMR spectroscopic data for the aglycone portion and the sugar chain of $\mathbf{4}$ and $\mathbf{3}$ showed superimposable resonances, except for the additional presence of a methyl group $\left(\delta_{\mathrm{C}} 54.2\right.$ and $\left.\delta_{\mathrm{H}} 3.28,3 \mathrm{H}, \mathrm{s}\right)$. In the $\mathrm{HMBC}$ spectrum the correlation between the methyl group at $\delta_{\mathrm{H}} 3.28$ and the carbon resonance at $\delta_{\mathrm{C}} 77.5(\mathrm{C}-11)$ allowed us to locate a methoxyl group at $\mathrm{C}-11$. The orientation of the $-\mathrm{OCH}_{3}$ function was concluded to be $\alpha$ according to the ROESY correlations between the proton signal at $\delta_{\mathrm{H}} 3.87(\mathrm{H}-$ $11, \mathrm{dd}, J=3.4,8.8 \mathrm{~Hz})$ and the proton signals at $\delta_{\mathrm{H}} 1.02(\mathrm{Me}-$ 25), and 1.03 (Me-26) (Figure 2). This result was in agreement
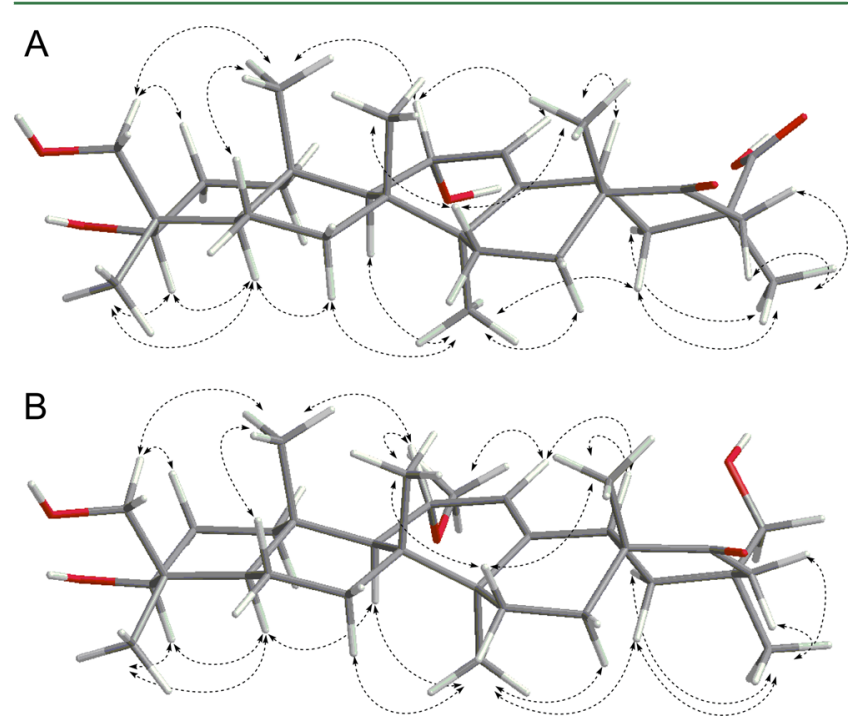

Figure 2. Selected ROESY correlations for the aglycone moieties of $\mathbf{1}$ (A) and 4 (B).

with literature data. ${ }^{25}$ Thus, the structure of 4 was established as 3 - $O$-[ $\beta$-D-glucopyranosyl- $(1 \rightarrow 2)-\beta$-D-glucuronopyranosyl $]$ $3 \beta, 24,30$-trihydroxy-11 $\alpha$-methoxyolean-12-en-22-one, and the proposed trivial name is sarosiensin IV.

The HR-MALDI/TOF mass spectrum of 1 supported a molecular formula of $\mathrm{C}_{42} \mathrm{H}_{64} \mathrm{O}_{17}$. The ESI-MS mass spectrum in negative ion mode showed the major ion peak at $m / z$ 839.4, which was assigned to $[\mathrm{M}-\mathrm{H}]^{-}$. In its MS/MS fragmentation pattern, the base peak at $m / z$ 659.2 $[\mathrm{M}-\mathrm{H}-180]^{-}$ corresponds to the loss of a hexose. The peak at $\mathrm{m} / z 501.2$ $[\mathrm{M}-\mathrm{H}-338]$ likely represents the loss of the entire C-3 carbohydrate side chain, thus suggesting it is composed of a hexose and a hexuronic acid.

A detailed comparison of NMR spectroscopic data for aglycone moiety of compounds $\mathbf{1}$ and $\mathbf{6}$ demonstrated great similarity, except for the presence of a carboxylic function at C$30\left(\delta_{\mathrm{C}} 183.8\right)$, instead of the methyl group in 6. The HMBC correlations between the proton signal at $\delta_{\mathrm{H}} 1.21$ and the carbon resonances at $\delta_{\mathrm{C}} 45.0$ (C-19), 47.7 (C-20), 48.8 (C-21), and 183.8 (C-30) suggested the linkage of a $-\mathrm{COOH}$ group to $\mathrm{C}-20$. The chemical shift of the methyl group attached to C-20 $\left(\delta_{\mathrm{C}} 27.1\right)$ supported a $30-\mathrm{COOH}$. Literature data report for an aglycone possessing $\mathrm{Me}-29$ and $\mathrm{COOH}-30$ the chemical shift of the methyl group at $\sim 27.0 \mathrm{ppm},{ }^{31,32}$ whereas for aglycones possessing $\mathrm{Me}-30$ and $\mathrm{COOH}-29$ the methyl group resonates at $\sim 20.0 \mathrm{ppm}^{24,33}$ The ROESY experiment, in which the correlations between the proton signal at $\delta_{\mathrm{H}} 1.21(\mathrm{Me}-29)$ and both $\mathrm{H}-19$ protons $\left(\delta_{\mathrm{H}} 1.96\right.$ and 2.08, each, $\left.\mathrm{m}\right)$ and the absence of a correlation between the proton signal at $\delta_{\mathrm{H}} 1.21(\mathrm{Me}-29)$ with the proton signal of $\mathrm{H}-18\left(\delta_{\mathrm{H}} 2.44, \mathrm{dd}, J=3.3,13.6 \mathrm{~Hz}\right)$ could be observed, confirmed the $\beta$ orientation of the $-\mathrm{COOH}$ (Figure 2).

For the sugar portion, compound $\mathbf{1}$ showed signals corresponding to the same sugar chain as compound 3. Thus, the structure of 1 was established as 3-O-[ $\beta$-D-glucopyranosyl$(1 \rightarrow 2)$ - $\beta$-D-glucuronopyranosyl]-3 $\beta, 11 \alpha, 24$-trihydroxyolean12-en-22-oxo-30-oic acid, and the proposed trivial name is sarosiensin I.

The molecular formula of 5 was established as $\mathrm{C}_{42} \mathrm{H}_{66} \mathrm{O}_{15}$ by HR-MALDI/TOF mass spectrum. The ESI-MS mass spectrum showed the major ion peak at $m / z 809.4$, which was assigned to $[\mathrm{M}-\mathrm{H}]^{-}$. Its MS/MS fragmentation pattern displayed ions at $m / z 629.3[\mathrm{M}-\mathrm{H}-180]^{-}$and $471.2[\mathrm{M}-\mathrm{H}-338]^{-}$, which correspond to the losses of a hexose and a hexose-hexuronic acid disaccharide, respectively. Also ${ }^{1,5} \mathrm{X}$ cross-ring fragmentation of a hexuronyl pyranose residue followed by a loss of water, which produced an ion at $m / z 539.1[\mathrm{M}-\mathrm{H}-270]^{-}$, was observed. The position of the glycosidic bond could be deduced from the ${ }^{0,2} \mathrm{X}$ cross-ring cleavage within the same residue, resulting in an ion at $m / z 675[\mathrm{M}-\mathrm{H}-135] .{ }^{34}$ This indicated that this bond involves a hydroxyl at C-2 of a hexuronic acid.

The ${ }^{1} \mathrm{H}$ and ${ }^{13} \mathrm{C}$ NMR signals for the aglycone moiety of $\mathbf{5}$ were almost superimposable on those of $\mathbf{2}$ except for the absence of the secondary alcoholic function at C-11. Consequently, the aglycone portion was identified as 3/,24,30-trihydroxyolean-12-en-22-one, known as wistariasapogenol A, previously isolated from Wisteria brachybotrys (family Fabaceae) ${ }^{30}$ However, it is reported here for the first time in Trifolium genus. The sugar portion of 5 was the same as of $\mathbf{1}, \mathbf{3}$, and 4 . Thus, 5 was identified as 3-O-[ $\beta$-D-glucopyranosyl- $(1 \rightarrow$ $2)$ - $\beta$-D-glucuronopyranosyl]-3 $\beta, 24,30$-trihydroxyolean-12-en22 -one, and the proposed trivial name is sarosiensin $\mathrm{V}$.

In the present work, seven triterpene glycosides never reported before, namely, sarosiensin I-VII, were isolated and characterized from the aerial parts of T. medium var. sarosiense. The base peak chromatogram obtained by negative-ion HPLCESI/MS of T. medium var. sarosiense saponins (Figure 3A) clearly shows that isolated compounds represent the most intense peaks in this fraction. Peaks at $m / z 839(1,4), 795(2)$, 825 (3), 809 (5), 647 (6), and 661 (7) correspond to the compounds identified in this work. Furthermore, the chromatogram shows also an intense peak at $m / z 941$, which showed a fragmentation pattern identical to that of soyasaponin $\mathrm{Bb}$ (soyasaponin $\mathrm{I}^{35,36}$ ). Due to the fact that this compound is quite common, and its structure is well-known, it was not purified in this work. However, soyasaponin $\mathrm{Bb}$ is a common saponin occurring in most Trifolium species, and in many of them soyasapogenol glycosides were the only saponins present. ${ }^{17-21}$ Therefore, T. medium var. sarosiense seems to be 


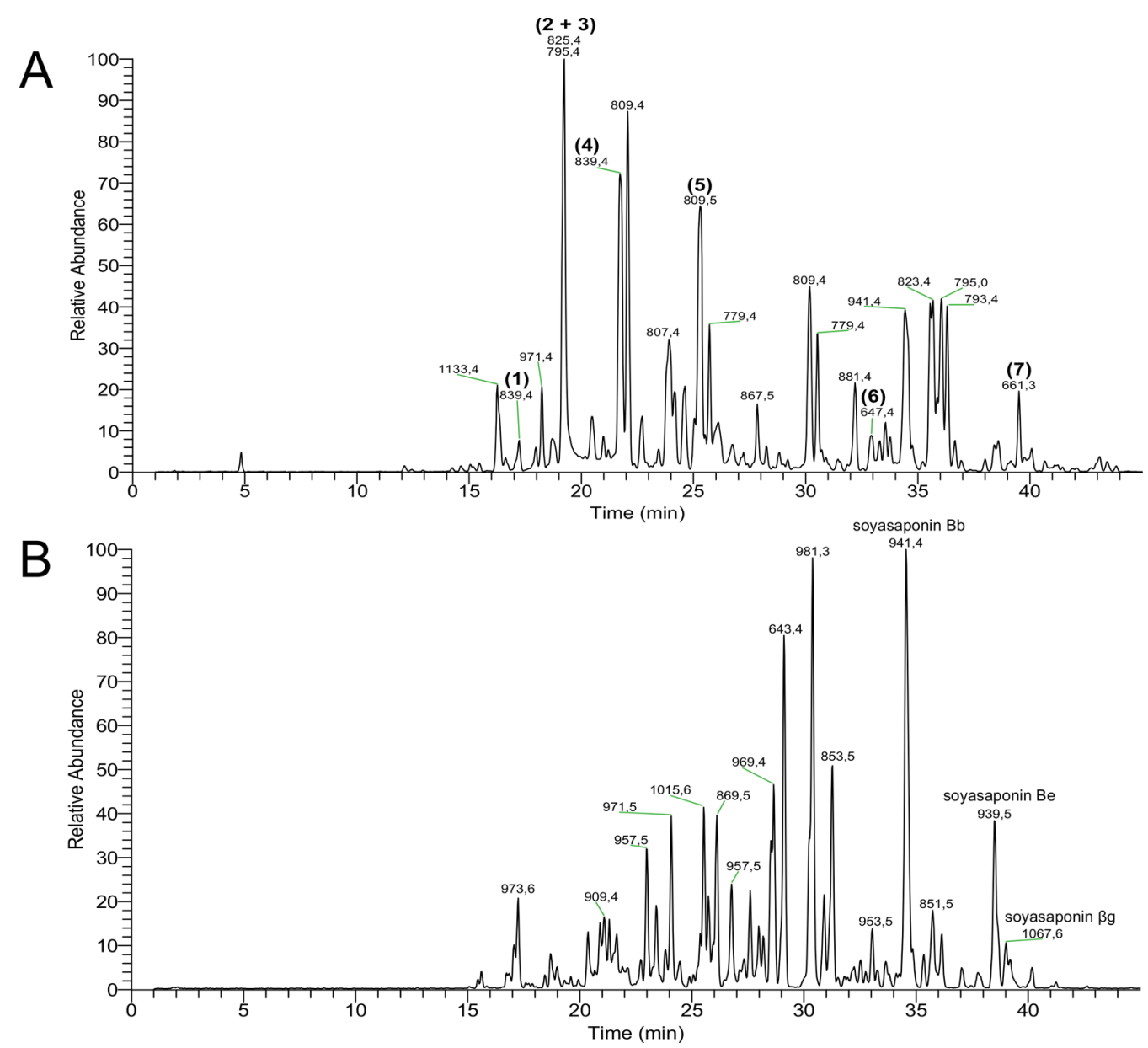

Figure 3. HPLC-ESI/MS base peak chromatograms of T. medium var. sarosiense (A) and T. medium var. medium (B) saponin fraction.

a unique species in the Trifolium genus, able to synthesize triterpene oleanane aglycones different from soyasapogenols.

Classification of zigzag clover taxa has not been conclusively resolved so far. Therefore, the phytochemical comparison of two mentioned subspecies of T. medium for their secondary metabolites might be of great interest, because it may contribute to resolving the doubts of species rank for $T$. medium var. sarosiense. Figure $3 \mathrm{~B}$ shows the base peak chromatogram obtained by the negative-ion HPLC-ESI/MS of T. medium var. medium saponins and its comparison to the analogous chromatogram of $T$. medium var. sarosiense, which clearly shows that their saponin profiles are significantly different. Both subspecies produce few soyasapogenol B and soyasapogenol E derivatives, such as soyasaponin $\mathrm{Bb}(m / z$ 941, RT $34.5 \mathrm{~min}), \mathrm{Bc}(\mathrm{m} / z$ 911, RT $34.3 \mathrm{~min}$, coeluting with $\mathrm{Bb})$, and $\mathrm{Be}(\mathrm{m} / z$ 939, RT $38.4 \mathrm{~min})$ as well as DDMP-conjugated soyasaponin $\beta \mathrm{g}(\mathrm{m} / z$ 1067, RT $38.9 \mathrm{~min})$. However, a majority of peaks from T. medium var. sarosiense extract were not found in other subspecies. Our former ${ }^{15,16}$ and present investigations of T. medium taxa show the existence of significant differences in a secondary metabolism of both zigzag clover subspecies, which may indicate their more distant relationship. Therefore, it seems to be more reasonable to follow databases and publications that classify $T$. medium var. sarosiense as a taxa species (T. sarosiense) separate from T. medium.

\section{ASSOCIATED CONTENT}

\section{Supporting Information}

NMR spectra $\left({ }^{1} \mathrm{H}\right.$ and ${ }^{13} \mathrm{C}$ NMR, HSQC, HMBC, $\left.{ }^{1} \mathrm{H}-{ }^{1} \mathrm{HCOSY}\right)$ for the new compounds $(1-7)$, including ROESY spectra for compounds $1,2,4,6$, and 7. This material is available free of charge via the Internet at http://pubs.acs.org.

\section{AUTHOR INFORMATION}

\section{Corresponding Author}

*(D.J.) E-mail: djedrejek@iung.pulawy.pl. Phone: +48 818863421, ext. 207. Fax: +48 818863421, ext. 295.

\section{Funding}

The work was supported from the European Union's Seventh Framework Programme projects PROFICIENCY (Contract 245751) and OSCAR (Contract 289277) and by the statutory activity $(1.06 ; 2012-2014)$ of the Institute of Soil Science and Plant Cultivation.

\section{Notes}

The authors declare no competing financial interest.

\section{ACKNOWLEDGMENTS}

We thank Prof. Dr. A. Garner of Genebank, Zentralinstitut für Pflanzengenetik und Kulturpflanzenforschung (Gatersleben, Germany), for providing us with authenticated Trifolium medium var. sarosiense seeds. 


\section{REFERENCES}

(1) Ellison, N. W.; Liston, A.; Steiner, J. J.; Williams, W. M.; Taylor, N. L. Molecular phylogenetics of the clover genus (Trifolium Leguminosae). Mol. Phylogenet. Evol. 2006, 39, 688-705.

(2) Zohary, M.; Heller, D. The Genus Trifolium; Backhuys Publishers: Kerkwerve, The Netherlands, 1984; 606 pp, ISBN 965-208-056-X.

(3) Bisby, F. A., Buckingham, J., Harborne, J. B., Eds. Phytochemical Dictionary of the Leguminosae; Chapman and Hall: London, UK, 1994.

(4) Cook, D. Medicago truncatula - a model in the making! Curr. Opin. Plant Biol. 1999, 2, 301-304.

(5) Tekeli, A. S.; Ates, E. The determination of agricultural and botanical characters of some annual clovers (Trifolium sp.). Bulg. J. Agric. Sci. 2003, 9, 505-508.

(6) Williams, W. M.; Nichols, S. N. Trifolium. In Wild Crop Relatives: Genomic and Breeding Resources Legume Crops and Forages; Kole, C., Ed.; Springer: Berlin, Germany, 2011; pp 249-272.

(7) Taylor, N. L.; Quesenberry, K. H. Red Clover Science; Kluwer Academic Publishers: Dordrecht, The Netherlands, 1996; pp 1-208, ISBN 0792338871.

(8) Taylor, N. L. Characterization of the United States germplasm collection of zigzag clover (Trifolium medium L.). Genet. Resour. Crop Evol. 1995, 42, 43-47.

(9) Catalogue of Life: indexing the world's known species, http:// www.catalogueoflife.org/col/details/species/id/11492849 (accessed Sept 17, 2013).

(10) ILDIS Legume Web, http://www.ildis.org/ LegumeWeb?version 10.01\&LegumeWeb\&tno 6548 (accessed Sept 17, 2013).

(11) Abberton, M. T. Interspecific hybridization in the genus Trifolium. Plant Breed. 2007, 126, 337-342.

(12) Tropicos, http://www.tropicos.org/Name/13034212 (accessed Sept 17, 2013).

(13) The International Plant Names Index, http://www.ipni.org/ ipni/plantnamesearchpage.do (accessed Sept 17, 2013).

(14) Janda, B.; Stochmal, A.; Montoro, P.; Piacente, S.; Oleszek, W. Phenolics in aerial parts of Persian clover Trifolium resupinatum. Nat. Prod. Commun. 2009, 4 (12), 1661-1664.

(15) Oleszek, W.; Stochmal, A. Triterpene saponins and flavonoids in the seeds of Trifolium species. Phytochemistry 2002, 61, 165-170.

(16) Oleszek, W.; Stochmal, A.; Janda, B. Concentration of isoflavones and other phenolics in the aerial parts of Trifolium species. J. Agric. Food Chem. 2007, 55, 8095-8100.

(17) Jurzysta, M.; Price, K. R.; Ridout, C.; Fenwick, G. R. The structure of four tritepenoid saponins isolated from the seeds of Trifolium incarnatum L. Acta Soc. Bot. Pol. 1989, 58, 575-582.

(18) Oleszek, W.; Jurzysta, M. Isolation, chemical characterization and biological activity of red clover (Trifolium pratense L.) root saponins. Acta Soc. Bot. Pol. 1986, 55, 247-252.

(19) Sakamoto, S.; Kofuji, S.; Kuroyanagi, M.; Ueno, A.; Sekita, S. Saponins from Trifolium repens L. Phytochemistry 1992, 31, 17731777.

(20) Simonet, A. M.; Stochmal, A.; Oleszek, W.; Macías, F. A. Saponins and polar compounds from Trifolium resupinatum $\mathrm{L}$. Phytochemistry 1999, 51, 1065-1067.

(21) Stochmal, A.; Oleszek, W. The changes of cyanogenic glucosides in white clover (Trifolium repens L.) during the growing season. J. Agric. Food Chem. 1997, 11, 4333-4336.

(22) De Tommasi, N.; Piacente, S.; Gacs Baitz, E.; De Simone, F.; Pizza, C.; Aquino, R. Triterpenoid saponins from Spergularia ramosa. J. Nat. Prod. 1998, 61, 323-327.

(23) Kapusta, I.; Stochmal, A.; Perrone, A.; Piacente, S.; Pizza, C.; Oleszek, W. Triterpene saponins from barrel medic (Medicago truncatula) aerial parts. J. Agric. Food Chem. 2005, 53, 2164-2170.

(24) Mahato, S. B.; Kundu, A. P. ${ }^{13} \mathrm{C}$ NMR spectra of pentacyclic triterpenoids. A compilation and some salient features. Phytochemistry 1994, 37, 1517-1575.

(25) Fujita, R.; Duan, H.; Takaishi, Y. Terpenoids from Tripterigyum hypoglaucum. Phytochemistry 2000, 53, 715-722.
(26) Miyao, H.; Sakai, Y.; Takeshita, T.; Kinjo, J.; Nohara, T. Triterpene Saponins from Abrus cantoniensis (Leguminosae). I. Isolation and characterization of four new saponins and a new sapogenol. Chem. Pharm. Bull. 1996, 44, 1222-1227.

(27) Mohamed, K. M.; Ohtani, K.; Kasai, R.; Yamasaki, K. Oleanene glycosides from seeds of Trifolium alexandrinum. Phytochemistry 1995, 40, 1237-1242.

(28) De Marino, S.; Borbone, N.; Iorizzi, M.; Esposito, G.; McClintock, J. B.; Zollo, F. Bioactive asterosaponins from the starfish Luidia quinaria and Psilaster cassiope. Isolation and structure characterization by two-dimensional NMR spectroscopy. J. Nat. Prod. 2003, 66, 515-519.

(29) Duan, H.; Takaishi, Y.; Momota, H.; Ohmoto, Y.; Taki, T.; Jia, Y.; Li, D. Triterpenoids from Tripterygium wilfordii. Phytochemistry 2000, 53, 805-810.

(30) Konoshima, T.; Kozuka, M.; Haruna, M.; Ito, K.; Kimura, T. Studies on the constituents of leguminous plants. XI. The structures of new triterpenoids from Wistaria brachybotrys Sieb. et Zucc. Chem. Pharm. Bull. 1989, 37 (6), 1550-1553.

(31) Altunkeyik, H.; Gulcemal, D.; Masullo, M.; Alankus-Calıskan, O.; Karayildirim, T.; Piacente, S. Triterpene glycosides from Cyclamen hederifolium. Phytochemistry 2012, 73, 127-133.

(32) Gulcemal, D.; Masullo, M.; Bedir, E.; Festa, M.; Karayildirim, T.; Alankus-Calıskan, O.; Piacente, S. Triterpene glycosides from Astragalus angustifolius. Planta Med. 2012, 78, 720-729.

(33) Gulcemal, D.; Masullo, M.; Napolitano, A.; Karayıldırım, T.; Bedir, E.; Alankus-Calıskan, O.; Piacente, S. Oleanane glycosides from Astragalus tauricolus: isolation and structural elucidation based on a preliminary liquid chromatography-electrospray ionization tandem mass spectrometry profiling. Phytochemistry 2013, 86, 184-194.

(34) Cuyckens, F.; Claeys, M. Mass spectrometry in the structural analysis of flavonoids. J. Mass Spectrom. 2004, 39 (1), 1-15.

(35) Waller, G. R.; West, P. R.; Cheng, C. S.; Ling, Y. C.; Chou, C. H. The occurrence of soyasaponin I in Vigna radiata L. (mungbean) sprouts as determined by fast atom bombardment, liquid secondary ion mass spectrometry, and linked scanning at constant B/E MS/MS. Bot. Bull. Acad. Sin. 1993, 34, 323-334.

(36) Jin, M.; Yang, Y.; Su, B.; Ren, Q. Rapid quantification and characterization of soyasaponins by high-performance liquid chromatography coupled with electrospray mass spectrometry. J. Chromatogr., A 2006, 1108, 31-37. 